\title{
Minimally invasive versus conventional mitral valve surgery: A propensity-matched comparison
}

\author{
Lars G. Svensson, MD, PhD, ${ }^{\mathrm{a}}$ Fernando A. Atik, MD, ${ }^{\mathrm{a}}$ Delos M. Cosgrove, $\mathrm{MD},{ }^{\mathrm{a}}$ \\ Eugene H. Blackstone, MD, ${ }^{\mathrm{a}, \mathrm{b}}$ Jeevanantham Rajeswaran, MSc, ${ }^{\mathrm{b}}$ Gita Krishnaswamy, MS, ${ }^{\mathrm{b}}$ Ung Jin, MD, ${ }^{\mathrm{a}}$ \\ A. Marc Gillinov, MD, ${ }^{\mathrm{a}}$ Brian Griffin, MD, ${ }^{\mathrm{c}}$ José L. Navia, MD, ${ }^{\mathrm{a}}$ Tomislav Mihaljevic, MD, ${ }^{\mathrm{a}}$ and \\ Bruce W. Lytle, MD
}

\begin{abstract}
Objective: Less invasive approaches to mitral valve surgery are increasingly used for improved cosmesis; however, few studies have investigated their effect on outcome. We sought to compare these minimally invasive approaches fairly with conventional full sternotomy by using propensity-matching methods.
\end{abstract}

\begin{abstract}
Methods: From January 1995 to January 2004, 2124 patients underwent isolated mitral valve surgery through a minimally invasive approach, and 1047 underwent isolated mitral valve surgery through a conventional sternotomy. Because there were important differences in patient characteristics, a propensity score based on 42 factors was used to obtain 590 well-matched patient pairs ( $56 \%$ of cases).
\end{abstract}

\begin{abstract}
Results: In-hospital mortality was similar for propensity-matched patients: $0.17 \%(1 / 590)$ for those undergoing minimally invasive surgery and $0.85 \%(5 / 590)$ for those undergoing conventional surgery $(P=.2)$. Occurrences of stroke $(P=.8)$, renal failure $(P>.9)$, myocardial infarction $(P=.7)$, and infection $(P=.8)$ were also similar. However, 24-hour mediastinal drainage was less after minimally invasive surgery (median, $250 \mathrm{vs} 350 \mathrm{~mL}$; $P<.0001)$, and fewer patients received transfusions $(30 \%$ vs $37 \%, P=.01)$. More patients undergoing minimally invasive surgery were extubated in the operating room $(18 \%$ vs $5.7 \%, P<.0001)$, and postoperative forced expiratory volume in 1 second was higher. Early after operation, pain scores were lower $(P<.0001)$ after minimally invasive surgery.
\end{abstract}

Conclusion: Within that portion of the spectrum of mitral valve surgery in which propensity matching was possible, minimally invasive mitral valve surgery had cosmetic, blood product use, respiratory, and pain advantages over conventional surgery, and no apparent detriments. Mortality and morbidity for robotic and percutaneous procedures should be compared with these minimally invasive outcomes. (J Thorac Cardiovasc Surg 2010;139:926-32)

丹 Supplemental material is available online.

In the mid-1990s, minimally invasive "keyhole" approaches for mitral valve operations were pioneered with the intent of reducing morbidity, postoperative pain, and blood loss;

From the Center for Aortic Surgery and Marfan and Connective Tissue Disorder Clinic, the Departments of Thoracic and Cardiovascular Surgery ${ }^{a}$ and Cardiovascular Medicine, ${ }^{\mathrm{c}}$ Heart and Vascular Institute, and the Department of Quantitative Health Sciences, ${ }^{b}$ Research Institute, Cleveland Clinic, Cleveland, Ohio.

Supported in part by the Kenneth Gee and Paula Shaw, PhD, Chair in Heart Research (held by Dr Blackstone); the Judith Dion Pyle Chair in Heart Valve Research (held by Dr Gillinov); and the John and Rosemary Brown Endowed Chair in Cardiovascular Medicine (held by Dr Griffin).

Disclosures: Dr Gillinov is a consultant to Edwards Lifesciences and receives honoraria for speaking from St Jude Medical, Inc. He has an equity interest in Viacor, Inc.

Received for publication Dec 3, 2008; revisions received July 15, 2009; accepted for publication Sept 17, 2009; available ahead of print Nov 30, 2009.

Address for reprints: Lars G. Svensson, MD, PhD, Department of Thoracic and Cardiovascular Surgery, Cleveland Clinic, 9500 Euclid Ave/Mail Stop J4-1, Cleveland, OH 44195 (E-mail: svenssl@ccf.org).

$0022-5223 / \$ 36.00$

Copyright $@ 2010$ Published by Elsevier Inc. on behalf of The American Association for Thoracic Surgery

doi:10.1016/j.jtcvs.2009.09.038 improving cosmesis; shortening hospital stay; and reducing cost compared with the 50-year-old conventional median sternotomy approach. ${ }^{1-8}$ Furthermore, it was believed that less spreading of the incision, no interference with the diaphragm, and less tissue dissection might improve outcomes, particularly respiratory function. ${ }^{7,8}$ Although clinical studies suggest that some of these benefits have been realized, there has been no confirmatory large study or randomized trial. ${ }^{1-10}$ Therefore, we performed a propensity-matched comparison of short- and long-term outcomes in patients who underwent minimally invasive mitral valve surgery with those who underwent conventional full sternotomy.

\section{MATERIALS AND METHODS Patients}

From January 1995 to January 2004, 3171 patients underwent isolated mitral valve surgery with or without tricuspid valve repair; patients undergoing concomitant aortic valve surgery, coronary artery bypass grafting, or reoperation were excluded, as were those with endocarditis. The more recently investigated approaches of right minithoracotomy and robotic procedures were not included because they were included in the armamentarium to treat mitral valve disease after this period. A minimally invasive approach was intended in $2124(67 \%)$ patients, and conventional full median 


\section{Abbreviations and Acronyms \\ $\mathrm{CL}=$ asymmetric $68 \%$ confidence limits \\ $\mathrm{FEV}_{1}=$ forced expiratory volume in 1 second \\ $\mathrm{MR}=$ mitral regurgitation}

sternotomy was intended in 1047 patients. Unmatched patients' mean age was $57 \pm 13$ years (range, $18-89$ years), and $58 \%$ were men.

Data were in part retrieved from the prospective Cardiovascular Information Registry and in part from each patient's medical record. These data were approved for use in research by the institutional review board, with patient consent waived.

\section{Surgical Technique}

Conventional general anesthesia was used in all patients, regardless of surgical approach. In those receiving a full median sternotomy, the mitral valve was usually visualized through an incision in the left atrium anterior to the right pulmonary veins. Patients who underwent minimally invasive surgery had a 3- to 4 -inch (8- to 10 -cm) skin incision. ${ }^{1,3,7}$ Three minimally invasive approaches were included in this study. From 1995 through 1996, a right paramedian incision was used that included division of the third and fourth costal cartilages (158 [8.4\%] patients) ${ }^{1}$; from 1997 onward, this changed to a $\mathbf{J}$ incision beginning at the sternal notch and ending at the fourth intercostal space (1635 [87\%] patients) ${ }^{7,8}$ From 1998 to 2004, 37 $(1.8 \%)$ patients had a partial right lower sternotomy; choice of approach was at the surgeon's discretion. In this study, more recently introduced approaches, such as robotic or lateral minithoracotomy, were added after completion of the study.

With these minimally invasive chest-wall incisions, the mitral valve was accessed through a transseptal incision. Routine mitral valve repair and replacement techniques were used, and all types of complete repairs were possible through the minimally invasive incision. ${ }^{1,8,10,11}$ Vacuum-assisted cardiopulmonary bypass with central cannulation was used in all patients. ${ }^{12}$ Intraoperative transfusions, anesthetic technique, and timing of extubation were at the anesthesiologist's discretion. Intraoperative and postoperative transfusion, extubation, and pain scores were not derived from protocols. Clearly, in the early phase of this study, there was a learning curve involved in developing the technique, which was, however, technically similar to conventional sternotomy.

\section{Study Design}

A number of differences in patient characteristics precluded direct comparison of outcomes (Table 1). Therefore, to reduce the influence of selection, we used propensity matching to approximate a randomized trial. ${ }^{13-15}$ In the spirit of such a trial, we followed the intent-to-treat principle, such that the $40(1.9 \%)$ cases with an intended minimally invasive approach who were converted to conventional sternotomy were retained in the minimally invasive group. Initially, a parsimonious model based on variables in Appendix 1 was formulated by means of logistic regression analysis with bagging for variable selection (see Table E1) to understand the drivers of patient selection. ${ }^{16}$ To this model were added nonsignificant variables to form a propensity model. From this, a propensity score was generated for each patient from a logistic regression model $(C=0.86)$ based on 42 preoperative variables and procedure variables that were predictable preoperatively (Appendix 1). Greedy matching based on the propensity score was used to identify 590 patient pairs for comparison (see Table E2). ${ }^{17}$ Figure 1 indicates the portion of the spectrum of propensity from which matched pairs were obtained, and Table E2 documents characteristics of patients for whom either minimally invasive or conventional approaches were more heterogeneously applied during the study period. Clearly, as seen from the figure, there is good overlap between the procedures after propen- sity adjustment. This strategy was repeated for the 2000-2004 cohort with spirometric values and pain scores, yielding 268 propensity-matched patient pairs.

\section{Outcomes}

Outcomes assessed included intraoperative support (myocardial ischemic and cardiopulmonary bypass times), postoperative in-hospital mortality and morbidity (defined in accordance with the Society of Thoracic Surgeons National Database http://www.ctsnet.org/file/rptDataSpecifications252_1_ ForVendorsPGS.pdf), blood product use, mediastinal drainage at 6 and 24 hours, hematocrit value at hospital discharge, time to extubation (which was at the discretion of attending anesthesiologists in either the operating room or intensive care unit), all incentive spirometric values after extubation, all pain scores, length of hospital stay, long-term survival, and recurrence of mitral regurgitation (MR) in patients undergoing repair.

Spirometry and pain scoring were performed and results were recorded prospectively from January 2000 to January 2004, during which time 536 matched patients underwent operations. Both spirometric values and pain scores were obtained routinely as part of clinical care from all patients after surgical intervention. Spirometry, consisting of forced expiratory volume in 1 second ([FEV 1$]$ in milliliters), was performed periodically by respiratory therapists using a Renaissance II bedside spirometer (Puritan Bennett, Carlsbad, Calif) until hospital discharge; a total of 2234 values were available for $417(78 \%)$ matched patients. $\mathrm{FEV}_{1}$ values were normalized to the percentage of predicted value by using the National Health and Nutrition Examination Survey algorithm. ${ }^{18}$ Pain intensity, ranging from 0 (none) to 10 (severe), was recorded by nursing staff from the patient's arrival in the intensive care unit to hospital discharge by using the extensively validated Wong-Baker visual-analog scale. ${ }^{19,20}$ A total of 18,061 pain scores were available for $454(85 \%)$ matched patients.

Survival was assessed by follow-up every 2 years by using an institutional review board-approved questionnaire supplemented by the Social Security Death Index. ${ }^{21,22}$ A total of 5296 patient-years of information was available for analyses among matched patients, with a mean follow-up of $4.5 \pm 2.5$ years; $25 \%$ of survivors were followed for more than 6.8 years, and $10 \%$ were followed for more than 8 years. For matched patients undergoing minimally invasive surgery, 2787 patient-years of follow-up were available for analyses, mean follow-up was $4.7 \pm 2.3$ years, and $10 \%$ were followed more than 7.9 years. For matched patients undergoing conventional sternotomy, 2509 patient-years of follow-up were available for analyses. Mean follow-up was $4.2 \pm 2.7$ years, and $10 \%$ were followed more than 8.4 years.

Recurrence of MR in patients undergoing repair was assessed by using the transthoracic echocardiographic grade of postoperative MR. A total of 2039 postoperative echocardiograms were available for 816 matched patients undergoing repair ( $90 \%$ of total matched patients undergoing repair), with a median follow-up of 1.3 months (minimum, 1 day; maximum, 14 years; Figure 2).

\section{Comparisons}

Categorical outcomes were compared by using either the $\chi^{2}$ or Fisher's exact test, and continuous outcomes were compared by using the $t$ test or Wilcoxon rank-sum nonparametric test for skewed distributions. To compare the temporal pattern of postoperative $\mathrm{FEV}_{1}$ across time, the repeated continuous values were analyzed longitudinally by using mixed-model regression, ${ }^{17}$ with autoregressive order 1 correlation structure to accommodate the correlated nature of the observations within each patient.

To compare the temporal pattern of postoperative pain across time, pain scores were combined into 5 categories because of low frequency of higher pain scores: 0 (pain score 0), 1 (pain scores 1-3), 2 (pain scores 4-6), 3 (pain scores 7 and 8), and 4 (pain scores 9 and 10). Pain score category was analyzed longitudinally by using a nonlinear cumulative logit mixed model for repeated measures that resolved a number of temporal components and 
TABLE 1. Patient characteristics and operative details by surgical approach: Overall

\begin{tabular}{|c|c|c|c|c|c|}
\hline \multirow[b]{2}{*}{ Variable } & \multicolumn{2}{|c|}{ Minimally invasive $(n=2124)$} & \multicolumn{2}{|c|}{ Conventional $(n=1047)$} & \multirow[b]{2}{*}{$P$ value } \\
\hline & No. & $\%$ & No. & $\%$ & \\
\hline \multicolumn{6}{|l|}{ Demography } \\
\hline Female sex & 805 & 38 & 522 & 50 & $<.0001$ \\
\hline Age $(y)$, mean $\pm S D$ & $56 \pm 13$ & & $59 \pm 14$ & & $<.0001$ \\
\hline $\mathrm{BMI}\left(\mathrm{kg} \cdot \mathrm{m}^{-2}\right)$, mean $\pm \mathrm{SD}$ & $26 \pm 4.0$ & & $27 \pm 5.4$ & & $<.0001$ \\
\hline NYHA functional class & & & & & $<.0001$ \\
\hline I & 588 & 28 & 146 & 14 & \\
\hline II & 1,234 & 58 & 560 & 53 & \\
\hline III & 251 & 12 & 260 & 25 & \\
\hline IV & 51 & 2.4 & 81 & 7.7 & \\
\hline \multicolumn{6}{|l|}{ Indication for operation } \\
\hline Degenerative & 1803 & 85 & $622 / 1046^{*}$ & 59 & $<.0001$ \\
\hline Ischemic & 12 & 0.56 & $36 / 1046^{*}$ & 3.4 & $<.0001$ \\
\hline Rheumatic & 196 & 9.2 & $201 / 1046^{*}$ & 19 & $<.0001$ \\
\hline Other & 113 & 5.3 & $187 / 1046^{*}$ & 18 & $<.0001$ \\
\hline \multicolumn{6}{|l|}{ Cardiac comorbidity } \\
\hline LV dysfunction & $107 / 2038 *$ & 5.2 & $209 / 944 *$ & 22 & $<.0001$ \\
\hline Tricuspid regurgitation $>$ moderate & $177 / 2062 *$ & 8.6 & $181 / 837 *$ & 22 & $<.0001$ \\
\hline Atrial fibrillation/flutter & 240 & 11 & 186 & 18 & $<.0001$ \\
\hline \multicolumn{6}{|l|}{ Noncardiac comorbidity } \\
\hline Hypertension & $733 / 2073 *$ & 35 & $449 / 967 *$ & 46 & $<.0001$ \\
\hline Treated diabetes & $33 / 2077 *$ & 1.6 & $75 / 997^{*}$ & 7.5 & $<.0001$ \\
\hline COPD & $255 / 2022 *$ & 13 & $224 / 702 *$ & 32 & $<.0001$ \\
\hline \multicolumn{6}{|l|}{ Procedure } \\
\hline Mitral valve repair & 1916 & 90 & 747 & 71 & $<.0001$ \\
\hline Tricuspid valve repair & 129 & 6.1 & 191 & 18 & $<.0001$ \\
\hline
\end{tabular}

$S D$, Standard deviation; $B M I$, body mass index; $N Y H A$, New York Heart Association; $L V$, left ventricular; $C O P D$, chronic obstructive pulmonary disease. *Number of patients with data available.

their shaping parameters. ${ }^{23}$ Each component was independently modulated by a time function with common random intercept. Survival was compared nonparametrically by using the Kaplan-Meier method and parametrically by using a temporal decomposition model. ${ }^{23}$ To compare temporal pattern of postoperative MR across time, we have used a nonlinear cumulative logit mixed model, as described above. Because of low frequency, MR grades $3+$ and $4+$ were collapsed together and treated as one category.

\section{Presentation}

Categorical variables are summarized as frequencies and percentages and continuous variables as means \pm standard deviations or as equivalent 15th, 50th (median), and 85th percentiles (for consistency with \pm 1 standard deviation) when data were skewed. Asymmetric $68 \%$ confidence limits (CLs) are consistent with \pm 1 standard error. All analyses were performed with SAS statistical software version 9.1 (SAS Institute, Inc, Cary, NC).

\section{RESULTS}

\section{Intraoperative Support}

Among propensity-matched patients, ischemic time was slightly longer after a minimally invasive approach ( $65 \pm$ 24 vs $62 \pm 23$ minutes, $P=.01$ ), and cardiopulmonary bypass time was equivalent ( $85 \pm 46$ vs $84 \pm 31$ minutes, $P=.9)$.

\section{In-hospital Mortality and Morbidity}

In-hospital mortality was $0.17 \%(\mathrm{CL}, 0.03 \%-0.56 \%)$ in the minimally invasive group and $0.85 \%(\mathrm{CL}, 0.48 \%-$
$1.4 \%)$ in the matched conventional group $(P=.2$, Table 2$)$. In-hospital complications occurred with similar frequency in matched groups (Table 2).

\section{Bleeding and Transfusion}

Return to the operating room for bleeding was similar in matched groups (Table 2); however, mediastinal drainage was lower at 6 and 24 hours after a minimally invasive approach $(100 \mathrm{~mL}$ [CL, 50-200 mL] and $250 \mathrm{~mL}$ [CL, 150$350 \mathrm{~mL}])$ than after conventional sternotomy $(150 \mathrm{~mL}$ [CL, $100-300 \mathrm{~mL}]$ and $350 \mathrm{~mL}$ [CL, $250-600 \mathrm{~mL}])$ at these times $(P<.0001)$. Transfusion was less frequent after minimally invasive surgery than after conventional surgery (Table 2). However, hematocrit values at discharge were slightly lower after minimally invasive surgery $(30 \% \pm$ $3.5 \%$ vs $31 \% \pm 3.7 \%, P<.0001)$.

\section{Respiratory Function}

A higher proportion of matched patients were extubated in the operating room after minimally invasive than conventional surgery $(18 \%$ vs $5.7 \%, P<.0001)$. Median hours to extubation were also shorter (4.8 hours [CL, 2.2-10 hours] vs 5.6 hours [CL, 3.0-14 hours], $P=.001)$. $\mathrm{FEV}_{1}$ was similar immediately after extubation; however, it remained 


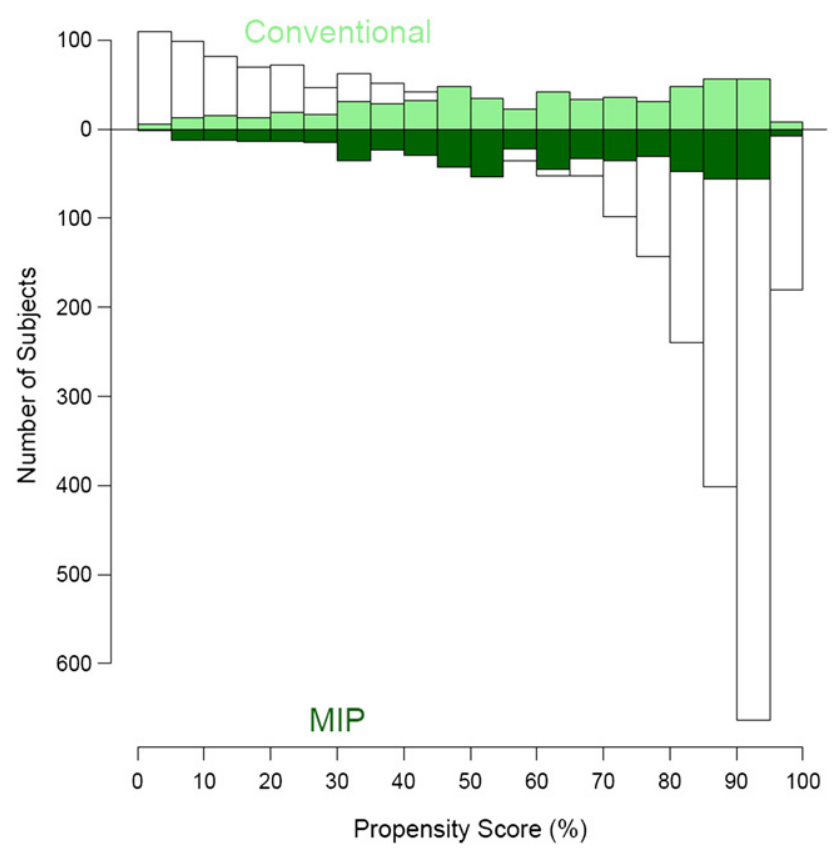

FIGURE 1. Mirrored histogram of distribution of propensity scores for conventional (bars above zero line) and minimally invasive (bars below zero line) approaches. The darkened area represents matched patient pairs, showing that they cover the complete spectrum of cases. MIP, Minimally invasive valve surgery.

constant in the minimally invasive group, but decreased in the conventional sternotomy group during the first 12 hours and increased thereafter (Figure 3).

\section{Postoperative Pain}

The general temporal pattern of pain score categories is illustrated in Figure 4, A. Over the first 24 postoperative hours, only about a third of patients were pain free, and this proportion increased to about $60 \%$ by day 3 and stabilized. Matched patients undergoing minimally invasive surgery had less pain in the first 24 hours after the operation $(P<.0001)$ but similar pain scores thereafter (Figure $4, B)$.

\section{Length of Stay}

Among matched patients, median postoperative length of stay was 6 days (CL, 4-10 days) after minimally invasive surgery and, similarly, 6 days (CL, 5-10 days) after conventional sternotomy $(P=.3)$.

\section{Survival}

Survival at 1,5 , and 8 years was $98 \%, 91 \%$, and $86 \%$ after minimally invasive surgery and $96 \%, 89 \%$, and $84 \%$ after conventional surgery among matched patients $(P=.07$, Figure 5).

\section{Return of Mitral Valve Regurgitation After Repair}

Proportions of patients in MR grade $3+$ or $4+$ at 1 and 5 years were $4 \%$ and $5 \%$ after minimally invasive surgery

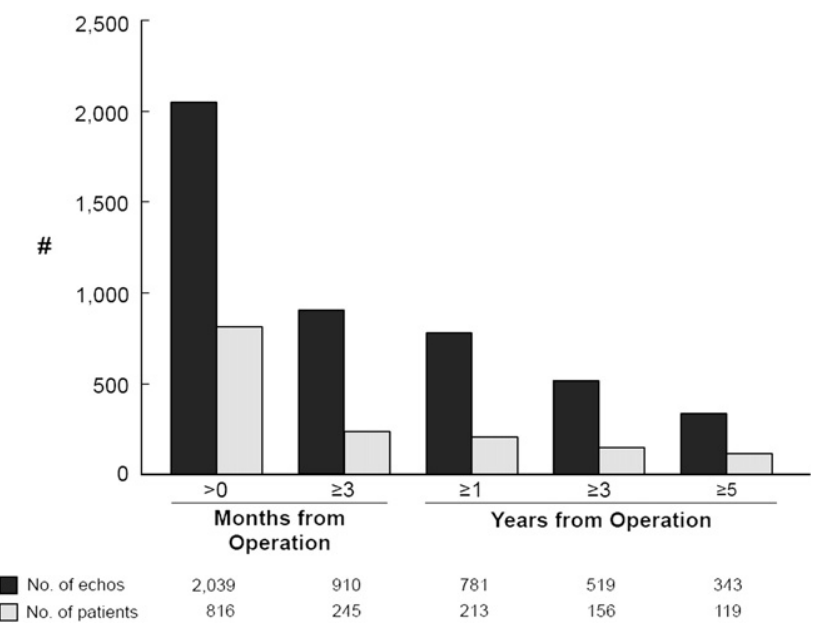

FIGURE 2. Number of patients with echocardiograms available at and beyond various time points and number of echocardiograms available for analysis. Black bars, echocardiograms; gray bars, patients.

and $6 \%$ and $7 \%$ after conventional surgery among matched patients $(P>.1$, Figure 6$)$.

\section{DISCUSSION}

Patients are increasingly requesting less invasive mitral valve procedures. In an attempt to achieve this and also maintain or improve on results of full median sternotomy, we pioneered the approach of paramedian or $\mathrm{J}$ incision partial sternotomies. ${ }^{1,7}$ Other minimally invasive and endoscopic approaches were also pioneered. ${ }^{2-6}$

When minimally invasive cardiac surgery was introduced in the 1990s, concern centered around longer operations, greater risk, and more complications for the perceived benefit of better cosmetic results, better respiratory function, and less pain and bleeding. Some approaches became less frequently used because of problems, such as with the paramedian incision, peripheral cannulation for cardiopulmonary bypass, and robotic surgery. ${ }^{1-10,24}$ Others, such as endoscopic or partial sternotomy, particularly the $\mathrm{J}$ incision, have become more widely adopted. ${ }^{1-10}$

\section{Principal Findings}

This study confirms the previously unproved perception that there are no disadvantages to minimally invasive surgery; that is, procedure time is not lengthened, risks are comparable or less, transfusions are less frequent, respiratory function is better, early postoperative pain is less, length of stay is comparable or shorter, long-term survival is comparable, and return of MR is uncommon and similar. Although there was no major difference in survival, it should be noted that hospital and 30-day survival was greater than $99 \%$ in both groups, and thus to show a difference in early postoperative risk would require a huge number of 
TABLE 2. In-hospital outcomes by surgical approach both overall and in propensity-matched patients

\begin{tabular}{|c|c|c|c|c|c|c|c|c|c|c|}
\hline \multirow[b]{3}{*}{ Outcome } & \multicolumn{5}{|c|}{ Overall } & \multicolumn{5}{|c|}{ Propensity-Matched } \\
\hline & \multicolumn{2}{|c|}{$\begin{array}{l}\text { Minimally invasive } \\
\quad(n=2124)\end{array}$} & \multicolumn{2}{|c|}{$\begin{array}{l}\text { Conventional } \\
(\mathrm{n}=1047)\end{array}$} & \multirow[b]{2}{*}{$P$ value } & \multicolumn{2}{|c|}{$\begin{array}{c}\text { Minimally invasive } \\
(\mathbf{n}=\mathbf{5 9 0})\end{array}$} & \multicolumn{2}{|c|}{$\begin{array}{l}\text { Conventional } \\
(\mathbf{n}=\mathbf{5 9 0})\end{array}$} & \multirow[b]{2}{*}{$P$ value } \\
\hline & No. & $\%$ & No. & $\%$ & & No. & $\%$ & No. & $\%$ & \\
\hline Death & 4 & 0.19 & 19 & 1.8 & $<.0001$ & 1 & 0.17 & 5 & 0.85 & .2 \\
\hline Stroke & 33 & 1.6 & 17 & 1.6 & .9 & 7 & 1.2 & 6 & 1.0 & .8 \\
\hline Renal failure & 5 & 0.24 & 14 & 1.3 & .0002 & 4 & 0.68 & 5 & 0.85 & $>.9$ \\
\hline Myocardial infarction & 9 & 0.42 & 4 & 0.38 & .9 & 4 & 0.68 & 2 & 0.34 & .7 \\
\hline Deep sternal wound infection & 14 & 0.66 & 4 & 0.38 & .3 & 6 & 1.02 & 4 & 0.68 & .8 \\
\hline Sepsis/septicemia & 17 & 0.8 & 31 & 3.0 & $<.0001$ & 8 & 1.4 & 12 & 2.0 & .4 \\
\hline Return to OR for bleeding & 64 & 3.0 & 46 & 4.4 & .04 & 20 & 3.4 & 26 & 4.4 & .4 \\
\hline $\mathrm{RBC}$ transfusion & $315 / 2022 *$ & 16 & $405 / 803 *$ & 50 & $<.0001$ & $155 / 517 *$ & 30 & $184 / 500^{*}$ & 37 & .01 \\
\hline Respiratory failure & 42 & 2.0 & 61 & 5.8 & $<.0001$ & 20 & 3.4 & 19 & 3.2 & .9 \\
\hline
\end{tabular}

$O R$, Operating room; $R B C$, red blood cell. *Number of patients with data available.

patients. Hence early and late operative results were not compromised.

Less perioperative bleeding and fewer blood transfusions are likely due to the less extensive mediastinal dissection required for the minimally invasive approach. Less pain is likely related to less surgical dissection, less spreading of the sternum, and no escalation of tension on the posterior rib head and costovertebral ligaments because the chest wall is not opened like a trap door. The better pulmonary function can be explained by no interference with the diaphragm or dissection along it. Also, with less chest wall pain, patients might have less splinting of the chest and thus can breathe more deeply.

Considerable interest has been directed recently toward percutaneous valves, including mitral valve coronary sinusbased devices or innovative leaflet approximation technolo-

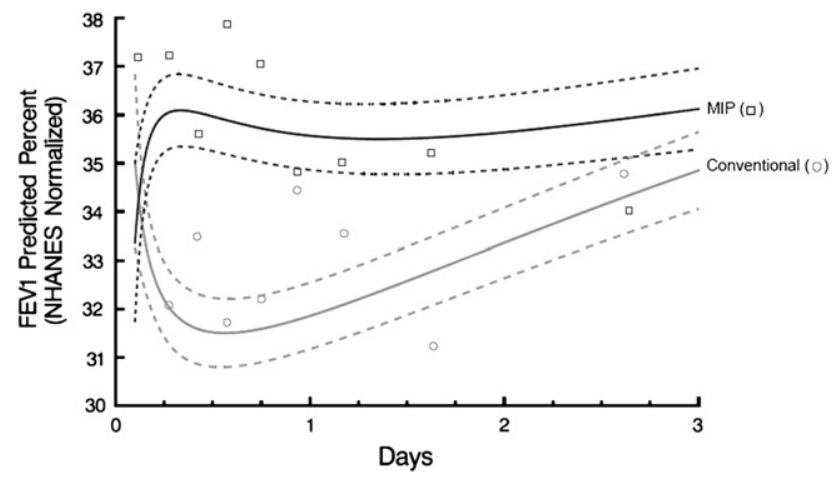

FIGURE 3. Temporal pattern of postextubation forced expiratory volume in 1 second $\left(F E V_{1}\right)$ as a percentage of predicted value after minimally invasive $(M I P)$ and conventional mitral valve surgery among propensitymatched patients. Solid lines are parametric estimates of temporal trend enclosed within dashed lines representing $68 \%$ confidence limits (equivalent to \pm 1 standard error). Symbols represent data grouped within time frames without regard for repeated assessment simply to provide crude verification of model fit. NHANES, National Health and Nutrition Examination Survey. gies. ${ }^{25-30}$ Mortality and morbidity results reported in this study should serve as a benchmark against which forthcoming percutaneous valve results are compared in otherwise good surgical candidates. Mortality of less than $1 \%$ and even $0.2 \%$ to
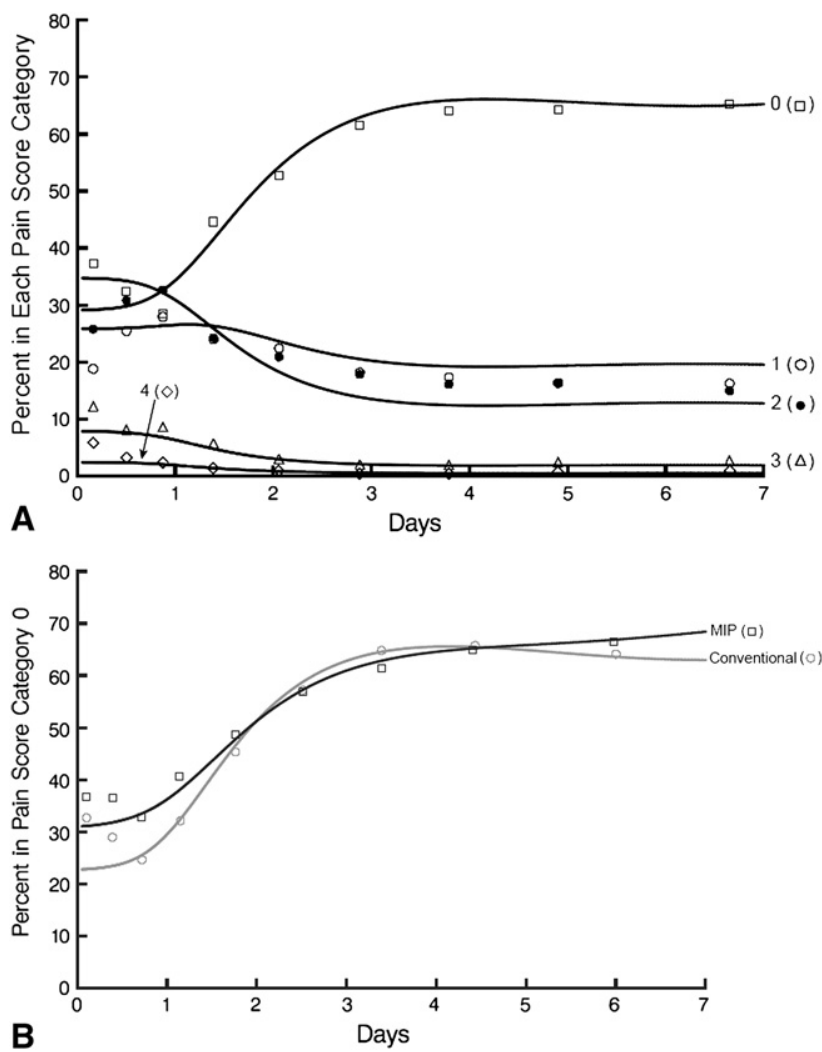

FIGURE 4. Temporal pattern of pain score categories after minimally invasive versus conventional mitral valve surgery among propensity-matched patients. Symbols represent data grouped within time frames without regard for repeated assessment simply to provide crude verification of model fit. Solid lines are parametric estimates of the percentage of patients in each category. A, All pain score categories. B, Proportion of patients without pain (category 0 ). 


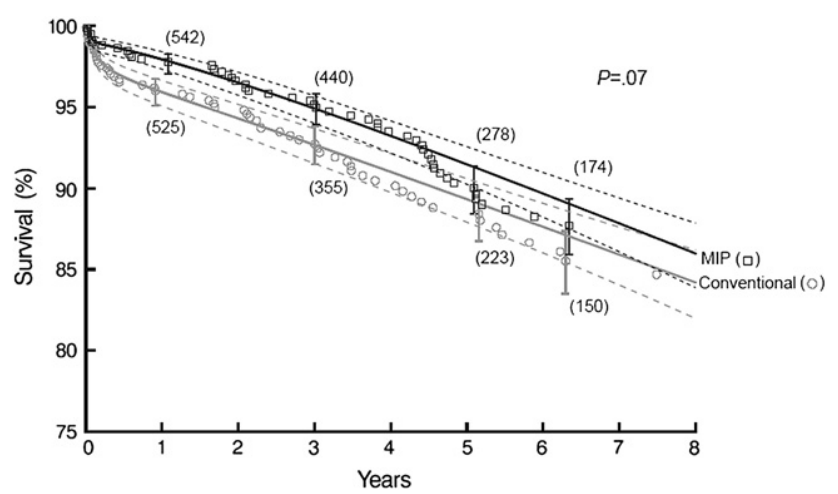

FIGURE 5. Survival after minimally invasive $(M I P)$ and conventional mitral valve surgery among propensity-matched patients. Each symbol represents a death, positioned actuarially; vertical bars represent $68 \%$ confidence limits; and numbers in parentheses represent patients remaining at risk. Solid lines are parametric estimates enclosed within dashed lines representing $68 \%$ confidence limits (equivalent to \pm 1 standard error).

$0.5 \%$ for minimally invasive surgery is to be expected, as well as stroke occurrence of less than $1.7 \%$. Furthermore, as we reported previously, all patients should have $1+$ or less MR after mitral valve repair. ${ }^{31-33}$ Whether percutaneous devices will convey a cost benefit, less pain, and shorter hospital stay over minimally invasive approaches remains to be seen, particularly with the likely higher costs of these devices. Since the closing date of this study (January 2006), we have increasingly used right minithoracotomy and robotic approaches. Indeed, currently, one quarter of our patients receive a conventional open approach, one quarter receive a mini-J incision, one quarter receive a minithoracotomy, and one quarter receive robotic surgery. We are currently conducting a prospective study to compare these approaches.

\section{Limitations}

Although heterogeneity in the use of minimally invasive mitral valve surgery provided the opportunity for comparisons with conventional surgery, clearly, as a group, patients undergoing conventional mitral valve surgery were sicker, with a less favorable prognosis (Figures E1-E3), than those undergoing minimally invasive surgery. When a propensity score was used to match patients, the comparison groups were intermediate in risk, and differences in most outcomes appeared to be explained by differences in patient characteristics rather than surgical approach. Indeed, like randomized trials that address only that portion of the spectrum of disease for which equipoise is present, propensity methods address only that portion of the spectrum for which heterogeneity in practice is discovered. However, as shown in Figure 1, matched patients cover the entire spectrum of propensity scores, although at both extremes of the spectrum, surgeons at Cleveland Clinic during the period of this study tended to use predominantly a minimally invasive or a conventional approach. Factors driving this decision are identified in

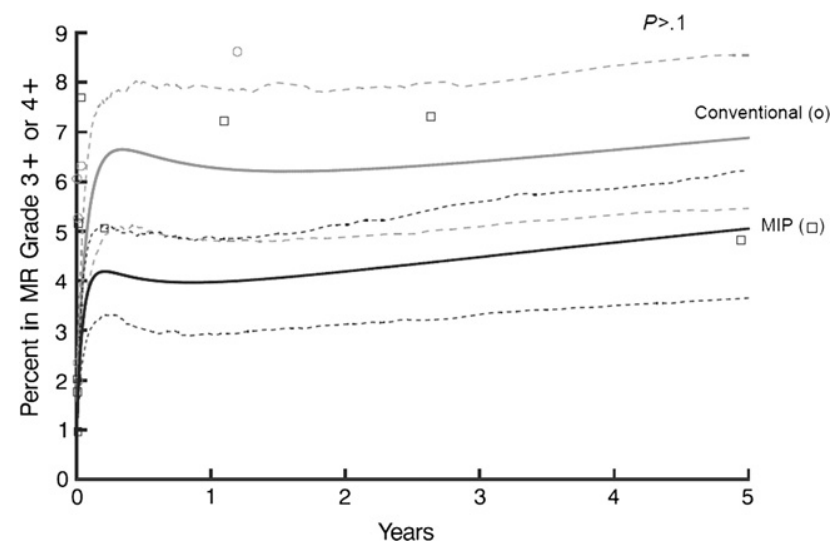

FIGURE 6. Proportion of patients with mitral regurgitation $(M R)$ grade $3+$ or $4+$ after minimally invasive $(M I P)$ and conventional mitral valve repair among propensity-matched patients. Symbols represent data grouped within time frame without regard for repeated assessment simply to provide crude verification of model fit. Solid lines are parametric estimates of the percentage of patients in MR grade $3+$ or $4+$ enclosed within $68 \%$ bootstrap percentile confidence limits.

Table 1: obesity, cerebral vascular disease, left ventricular function, acuity, cause of disease, tricuspid valve regurgitation, era of operation, and intent to repair rather than replace the valve. We acknowledge that selection bias cannot be completely reversed by using propensity-based methods and, in this study, cannot completely overcome distinct surgeon preferences. Because treatment was not masked, patients' self-reporting of pain scores might have been biased as well. This is also a single-institution study, which limits its generalizability. Nevertheless, timing to extubation, spirometric values, and pain scores would largely have been uninfluenced by potential surgeon biases because these were determined or routinely collected by respiratory therapists, anesthesiologists, or nurses.

\section{CONCLUSION}

Minimally invasive mitral valve surgery has cosmetic, blood product use, respiratory, and pain advantages and no apparent detriments. We routinely use the approach for most complex mitral valve procedures, excluding those requiring additional procedures, such as coronary artery or aortic surgery. For patients with localized P2-related regurgitation, we tend to perform valve repair using a robotic approach. We are, however, prospectively evaluating the options of a right minimally invasive thoracotomy and robotic approaches.

\section{References}

1. Cosgrove DM 3rd, Sabik JF, Navia JL. Minimally invasive valve operations. Ann Thorac Surg. 1998;65:1535-9.

2. Gundry SR, Shattuck OH, Razzouk AJ, del Rio MJ, Sardari FF, Bailey LL. Facile minimally invasive cardiac surgery via ministernotomy. Ann Thorac Surg. 1998; 65:1100-4. 
3. Cohn LH, Adams DH, Couper GS, Bichell DP, Rosborough DM, Sears SP, et al. Minimally invasive cardiac valve surgery improves patient satisfaction while reducing costs of cardiac valve replacement and repair. Ann Surg. 1997;226:421-8.

4. Chitwood WR Jr, Wixon CL, Elbeery JR, Moran JF, Chapman WH, Lust RM. Video-assisted minimally invasive mitral valve surgery. $J$ Thorac Cardiovasc Surg. 1997; 114:773-82

5. Schroeyers P, Wellens F, De Geest R, Degrieck I, Van Praet F, Vermeulen Y, et al. Minimally invasive video-assisted mitral valve surgery: our lessons after a 4-year experience. Ann Thorac Surg. 2001;72:S1050-4.

6. Grossi EA, Galloway AC, LaPietra A, Ribakove GH, Ursomanno P, Delianides J, et al. Minimally invasive mitral valve surgery: a 6-year experience with 714 patients. Ann Thorac Surg. 2002;74:660-4.

7. Svensson LG. Minimal-access “J”" or " j", sternotomy for valvular, aortic, and coronary operations or reoperations. Ann Thorac Surg. 1997;64:1501-3.

8. Svensson LG, D'Agostino RS. Minimal-access aortic and valvular operations, including the 'J/j"' incision. Ann Thorac Surg. 1998;66:431-5.

9. Svensson LG, D'Agostino RS. "J' incision minimal-access valve operations. Ann Thorac Surg. 1998;66:1110-2.

10. Svensson LG, Nadolny EM, Kimmel WA. Minimal access aortic surgery including re-operations. Eur J Cardiothorac Surg. 2001;19:30-3.

11. Gillinov AM, Cosgrove DM. Minimally invasive mitral valve surgery: mini-sternotomy with extended transseptal approach. Semin Thorac Cardiovasc Surg. 1999;11:206-11.

12. Banbury MK, White JA, Blackstone EH, Cosgrove DM 3rd. Vacuum-assisted venous return reduces blood usage. J Thorac Cardiovasc Surg. 2003;126:680-7.

13. Rosenbaum PR, Rubin DB. The central role of the propensity score in observational studies for causal effects. Biometrika. 1983;70:41-55.

14. Rubin DB. The design versus the analysis of observational studies for causal effects: parallels with the design of randomized trials. Stat Med. 2007;26:20-36.

15. Blackstone EH. Comparing apples and oranges. J Thorac Cardiovasc Surg. 2002; 123:8-15.

16. Breiman L. Bagging predictors. Machine Learning. 1996;24:123-40.

17. Bergstralh EJ, Konsanke JL. Computerized matching of cases to controls. Technical report No. 56. Department of Health Science Research. Rochester, Minn: Mayo Clinic; 1995.

18. Mannino DM, Buist AS, Petty TL, Enright PL, Redd SC. Lung function and mortality in the United States: data from the First National Health and Nutrition Examination Survey follow up study. Thorax. 2003;58:388-93.

19. Wong DL, Baker CM. Pain in children: comparison of assessment scales. Pediatr Nurs. 1988;14:9-17.

20. Bieri D, Reeve RA, Champion GD, Addicoat L, Ziegler JB. The Faces Pain Scale for the self-assessment of the severity of pain experienced by children: develop- ment, initial validation, and preliminary investigation for ratio scale properties. Pain. 1990;41:139-50.

21. Boyle CA, Decoufle P. National sources of vital status information: extent of coverage and possible selectivity in reporting. Am J Epidemiol. 1990;131:160-8.

22. Newman TB, Brown AN. Use of commercial record linkage software and vital statistics to identify patient deaths. J Am Med Inform Assoc. 1997;4:233-7.

23. Blackstone EH, Naftel DC, Turner ME Jr. The decomposition of time-varying hazard into phases, each incorporating a separate stream of concomitant information. J Am Stat Assoc. 1986;81:615-24.

24. Ryan WH, Dewey TM, Mack MJ, Herbert MA, Prince SL. Mitral valve surgery using the classical "heartport"' technique. J Heart Valve Dis. 2005;14:709-14.

25. Mack MJ. New techniques for percutaneous repair of the mitral valve. Heart Fail Rev. 2006;11:259-68.

26. Silvestry FE, Rodriguez LL, Herrmann HC, Rohatgi S, Weiss SJ, Stewart WJ, et al. Echocardiographic guidance and assessment of percutaneous repair for mitral regurgitation with the Evalve MitraClip: lessons learned from EVEREST I. $J$ Am Soc Echocardiogr. 2007;20:1131-40.

27. Dubreuil O, Basmadjian A, Ducharme A, Thibault B, Crepeau J, Lam JY, et al. Percutaneous mitral valve annuloplasty for ischemic mitral regurgitation: first in man experience with a temporary implant. Catheter Cardiovasc Interv. 2007; 69:1053-61.

28. Daimon M, Gillinov AM, Liddicoat JR, Saracino G, Fukuda S, Koyama Y, et al. Dynamic change in mitral annular area and motion during percutaneous mitral annuloplasty for ischemic mitral regurgitation: preliminary animal study with realtime 3-dimensional echocardiography. J Am Soc Echocardiogr. 2007;20:381-8.

29. Webb JG, Harnek J, Munt BI, Kimblad PO, Chandavimol M, Thompson CR, et al. Percutaneous transvenous mitral annuloplasty: initial human experience with device implantation in the coronary sinus. Circulation. 2006;113:851-5.

30. Choure AJ, Garcia MJ, Hesse B, Sevensma M, Maly G, Greenberg NL, et al. In vivo analysis of the anatomical relationship of coronary sinus to mitral annulus and left circumflex coronary artery using cardiac multidetector computed tomography: implications for percutaneous coronary sinus mitral annuloplasty. J Am Coll Cardiol. 2006;48:1938-45.

31. Dumont E, Gillinov AM, Blackstone NW, Sabik JF 3rd, Svensson S, Mihaljevic T, et al. Reoperation after mitral valve repair for degenerative disease. Ann Thorac Surg. 2007;84:444-50.

32. Gillinov AM, Bakaeen F, McCarthy PM, Blackstone EH, Rajeswaran J, Pettersson G, et al. Surgery for paroxysmal atrial fibrillation in the setting of mitral valve disease: a role for pulmonary vein isolation? Ann Thorac Surg. 2006;81:19-28.

33. Gillinov AM, Cosgrove DM, Blackstone EH, Diaz R, Arnold JH, Lytle BW, et al. Durability of mitral valve repair for degenerative disease. $J$ Thorac Cardiovasc Surg. 1998;116:734-43.

APPENDIX 1. Variables used in analyses

\section{Preoperative}

Demographic: Age $(\mathrm{y}){ }^{*}{ }^{*}$ sex, ${ }^{*}$ weight $(\mathrm{kg})$, height $(\mathrm{cm})$, body surface area $\left(\mathrm{m}^{2}\right)$, body mass index $\left(\mathrm{kg} \cdot \mathrm{m}^{-2}\right)^{*}$

Symptoms: NYHA functional class (I-IV)*

Ventricular dysfunction: Previous myocardial infarction,* degree of left ventricular dysfunction,* left ventricular ejection fraction (\%)

Mitral valve pathology: Mitral valve regurgitation, ${ }^{*}$ mitral valve stenosis*

Mitral valve disease: Rheumatic,* degenerative,* ischemic,* congenital

Other valve pathology: Tricuspid valve regurgitation,* pulmonary valve regurgitation*

Coronary anatomy: Left main trunk disease ( $\%$ stenosis), ${ }^{*}$ left anterior descending coronary artery system disease (maximum \% stenosis), ${ }^{*}$ right coronary artery system disease (maximum \% stenosis), ${ }^{*}$ left circumflex coronary artery system disease (maximum \% stenosis)*

Other cardiac comorbidity: Atrial fibrillation,* complete heart block,* ventricular arrhythmia*

Noncardiac comorbidity: Hypertension, ${ }^{*}$ treated diabetes, ${ }^{*}$ peripheral arterial disease, ${ }^{*}$ stroke, ${ }^{*}$ carotid disease, ${ }^{*}$ popliteal disease, ${ }^{*}$ endocarditis, ${ }^{*}$ smoking, ${ }^{*}$ renal disease, ${ }^{*}$ creatinine $\left(\mathrm{mg} \cdot \mathrm{dL}^{-1}\right), *$ blood urea nitrogen $\left(\mathrm{mg} \cdot \mathrm{dL}^{-1}\right),{ }^{*}$ bilirubin $\left(\mathrm{mg} \cdot \mathrm{dL}^{-1}\right),{ }^{*}$ hematocrit $(\%) *$

Experience: Date of operation (years since January 1, 1995)*

Intraoperative

Mitral valve procedure: Repair,* replacement, prosthesis manufacturer*

Other procedure: Tricuspid valve repair*

Surgeon: A, B, C,* D, ${ }^{*} \mathrm{E}, * \mathrm{~F},{ }^{*} \mathrm{G}, * \mathrm{H}^{*}$

NYHA, New York Heart Association. *Variables included in propensity score. 


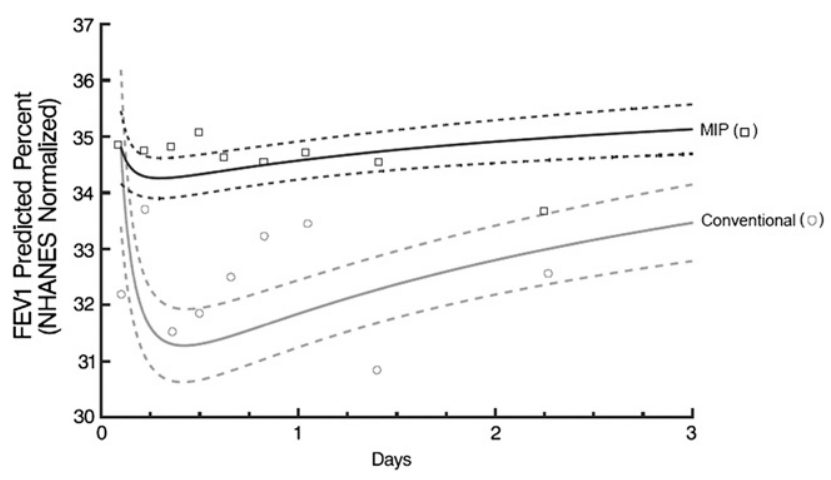

FIGURE E1. Temporal pattern of postextubation forced expiratory volume in 1 second $\left(F E V_{1}\right)$ as a percentage of predicted value after minimally invasive $(M I P)$ and conventional mitral valve surgery among all patients. Solid lines are parametric estimates of temporal trend enclosed within dashed lines representing $68 \%$ confidence limits (equivalent to \pm 1 standard error). Symbols represent data grouped within time frames without regard for repeated assessment simply to provide crude verification of model fit. NHANES, National Health and Nutrition Examination Survey.

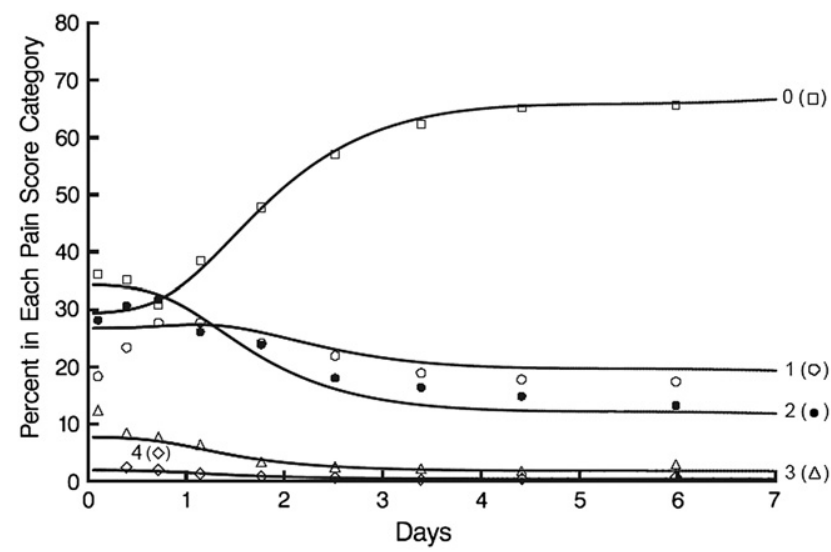

FIGURE E2. Temporal pattern of pain score categories after minimally invasive versus conventional mitral valve surgery among all patients. Symbols represent data grouped within time frames without regard for repeated assessment simply to provide crude verification of model fit. Solid lines are parametric estimates of the percentage of patients in each category.

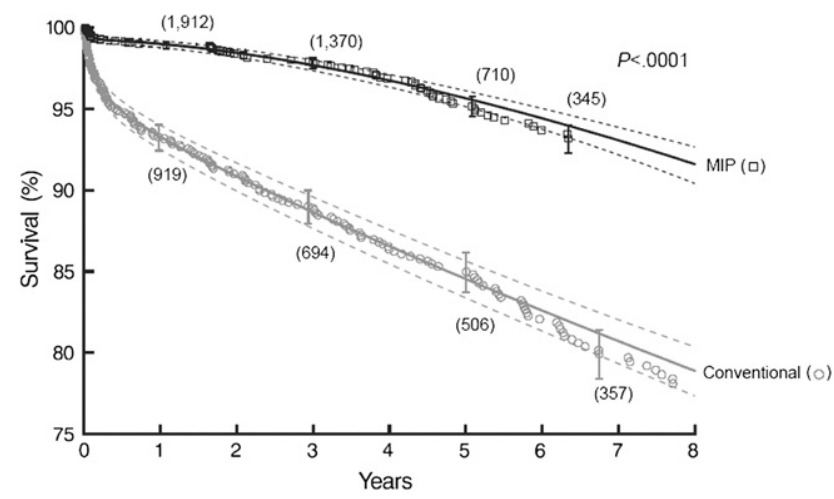

FIGURE E3. Survival after minimally invasive $(M I P)$ and conventional mitral valve surgery among all patients. Each symbol represents a death, positioned actuarially; vertical bars represent $68 \%$ confidence limits; and numbers in parentheses represent patients remaining at risk. Solid lines are parametric estimates enclosed within dashed lines representing $68 \%$ confidence limits (equivalent to \pm 1 standard error). 
TABLE E1. Parsimonious model of factors associated with the minimally invasive versus conventional approach for mitral valve surgery*

\begin{tabular}{lccc}
\hline \multicolumn{1}{c}{ Factor } & Coefficient \pm SD & P value & \\
\hline Higher likelihood of conventional approach & & & \\
$\quad$ Larger BMI $\ddagger$ & $1.9 \pm 0.28$ & $<.0001$ & 99 \\
Carotid disease & $0.80 \pm 0.16$ & $<.0001$ & 48 \\
Greater LV dysfunction & $0.52 \pm 0.054$ & $<.0001$ & 99 \\
Higher NYHA functional class§ & $0.61 \pm 0.14$ & $<.0001$ & 90 \\
Tricuspid valve repair & $0.88 \pm 0.15$ & $<.0001$ & 60 \\
Earlier date of operation|| & $3.5 \pm 0.21$ & & 100 \\
Higher likelihood of minimally invasive approach & & $<.0001$ & .007 \\
MV repair & $1.02 \pm 0.13$ & 98 \\
Degenerative MV etiology & $0.33 \pm 0.12$ & 89 \\
\hline
\end{tabular}

$S D$, Standard deviation; $B M I$, body mass index; $L V$, left ventricular; $N Y H A$, New York Heart Association; $M V$, mitral valve. *Obtained by means of logistic regression with variable selection by bagging. ${ }^{16} \dagger$ Frequency of occurrence in 1000 bootstrap models. $\ddagger \mathrm{BMI}^{2}$, squared transformation. $\S$ Ln(NYHA functional class), logarithmic transformation. ||Ln(interval from January 1, 1995, to date of operation), logarithmic transformation.

TABLE E2. Patient characteristics and operative details by surgical approach: Propensity-matched pairs

\begin{tabular}{|c|c|c|c|c|c|c|c|c|c|c|}
\hline \multirow[b]{3}{*}{ Variable } & \multicolumn{5}{|c|}{ Propensity matched } & \multicolumn{5}{|c|}{ Unmatched } \\
\hline & \multicolumn{2}{|c|}{$\begin{array}{c}\text { Minimally invasive } \\
(n=590) \\
\end{array}$} & \multicolumn{2}{|c|}{$\begin{array}{c}\text { Conventional } \\
(\mathbf{n}=\mathbf{5 9 0}) \\
\end{array}$} & \multirow[b]{2}{*}{$P$ value } & \multicolumn{2}{|c|}{$\begin{array}{c}\text { Minimally invasive } \\
(\mathrm{n}=\mathbf{1 5 3 4}) \\
\end{array}$} & \multicolumn{2}{|c|}{$\begin{array}{c}\text { Conventional } \\
(n=457) \\
\end{array}$} & \multirow[b]{2}{*}{$P$ value } \\
\hline & No. & $\%$ & No. & $\%$ & & No. & $\%$ & No. & $\%$ & \\
\hline \multicolumn{11}{|l|}{ Demography } \\
\hline Female sex & 276 & 47 & 267 & 45 & 6 & 529 & 34 & 255 & 56 & $<.0001$ \\
\hline Age $(y)$, mean $\pm S D$ & $59 \pm 13$ & & $59 \pm 14$ & & 6 & $55 \pm 13$ & & $60 \pm 17$ & & $<.0001$ \\
\hline BMI $\left(\mathrm{kg} \cdot \mathrm{m}^{-2}\right)$, mean $\pm \mathrm{SD}$ & $26 \pm 4.8$ & & $26 \pm 5.3$ & & .9 & $25 \pm 3.7$ & & $27 \pm 5.4$ & & $<.0001$ \\
\hline NYHA functional class & & & & & .7 & & & & & $<.0001$ \\
\hline I & 99 & 17 & 94 & 16 & & 489 & 32 & 52 & 11 & \\
\hline II & 350 & 59 & 352 & 60 & & 884 & 58 & 208 & 46 & \\
\hline III & 114 & 19 & 123 & 21 & & 137 & 8.9 & 137 & 30 & \\
\hline IV & 27 & 4.6 & 21 & 3.6 & & 24 & 1.6 & 60 & 13 & \\
\hline \multicolumn{11}{|l|}{ Indication for operation } \\
\hline Degenerative & 403 & 68 & $414 / 589^{*}$ & 70 & .5 & 1400 & 91 & 208 & 46 & $<.0001$ \\
\hline Rheumatic & 98 & 17 & $89 / 589 *$ & 15 & .5 & 98 & 6.4 & 112 & 25 & $<.0001$ \\
\hline Ischemic & 11 & 1.9 & $13 / 589 *$ & 2.2 & .7 & 1 & 0.07 & 23 & 5.03 & $<.0001$ \\
\hline Other & 78 & 13 & $73 / 589 *$ & 12 & .7 & 35 & 2.3 & 114 & 25 & $<.0001$ \\
\hline \multicolumn{11}{|l|}{ Cardiac comorbidity } \\
\hline LV dysfunction & $68 / 556^{*}$ & 12 & $66 / 548^{*}$ & 12 & .6 & $39 / 1482 *$ & 2.6 & $143 / 396^{*}$ & 34 & $<.0001$ \\
\hline Tricuspid regurgitation $>$ moderate & $84 / 532 *$ & 16 & $80 / 525^{*}$ & 15 & $>.9$ & $93 / 1530^{*}$ & 6.1 & $101 / 312^{*}$ & 32 & $<.0001$ \\
\hline Atrial fibrillation/flutter & 101 & 17 & 99 & 17 & .9 & 139 & 9.1 & 87 & 19 & $<.0001$ \\
\hline \multicolumn{11}{|l|}{ Noncardiac comorbidity } \\
\hline Hypertension & $246 / 575^{*}$ & 43 & $235 / 552^{*}$ & 42 & $>.9$ & $487 / 1498 *$ & 33 & $214 / 415^{*}$ & 52 & $<.0001$ \\
\hline Treated diabetes & $23 / 562 *$ & 4.1 & $25 / 568 *$ & 4.4 & .8 & $10 / 1515^{*}$ & 0.66 & $50 / 429 *$ & 12 & $<.0001$ \\
\hline COPD & $106 / 493^{*}$ & 22 & $113 / 487^{*}$ & 23 & .5 & $149 / 1529 *$ & 9.7 & $111 / 215^{*}$ & 52 & $<.0001$ \\
\hline \multicolumn{11}{|l|}{ Procedure } \\
\hline Mitral valve repair & 453 & 77 & 452 & 77 & .9 & 1463 & 95 & 295 & 65 & $<.0001$ \\
\hline Tricuspid valve repair & 78 & 13 & 73 & 12 & .7 & 51 & 3.3 & 118 & 26 & $<.0001$ \\
\hline
\end{tabular}

$S D$, Standard deviation; $B M I$, body mass index; $N Y H A$, New York Heart Association; $L V$, left ventricular; $C O P D$, chronic obstructive pulmonary disease. *Number of patients with data available. 